\title{
Discussion on Experimental Animation Teaching
}

\author{
Hongjuan Sun \\ School of Art and Design \\ Huanghe Science and Technology College \\ Zhengzhou, Henan, China 450063
}

\begin{abstract}
In combination with course features of Experimental Animation, this paper discusses how to apply animation theory in course teaching and how to improve students' innovative ability and artistic culture.
\end{abstract}

Keywords-Experimental Animation; law of motion; innovative ability; artistic culture

\section{INTRODUCTION}

With animation industrialization, more and more colleges set up animation major and enroll the Experimental Animation in specialty practice course system. Experimental Animation is a course of high practicability and operability with little investment and low cost, making it suitable to popularize in animation teaching. In the process of making experimental animation works, students can perceive and comprehend law of things and phenomena and it emerges directly in a short period of time. It not only cultivates students' participating spirit, but also lays a solid practice foundation for their future study of animation major. However, students usually are in a passive status in theoretical teaching and practice. Some problems should be highlighted in teaching, like how to mobilize students' initiative, positivity and creativity, how to develop and innovate the course teaching methods, and how to cultivate and enhance students' aesthetic judgment and artistic culture from various aspects. In combination with teaching practice, I'd like to talk about my personal outlook and some teaching results in terms of these problems.

\section{Strengthen Students' Basic Theoretical KNOWLEDGE OF ANIMATION}

Experimental animation refers to animation works at the stage of exploration and it is the earlier stage of concretization formation. Manifestation of abstract conception occupies a lot of space. In early phase of animation development, under the situation of lack of theory and technique, animation only belongs to experimental works of a small part of pioneer artists advocating personal freedom with innovative spirit. They disdain obeying existed display rules and they create with a spell of enthusiasm. With time goes on and advance in science and technology, animation gradually develops into an industry, its theoretical system gradually becomes mature and making technology and tools become more modernized. However, animation education can't break away from the most basic theoretical knowledge. Therefore, it is an essential link in teaching to strengthen students' theoretical knowledge.
Law of motion is the most basic part of animation knowledge. Animation of any form can't break away from law of animation motion. Then, how to make students master correct law of motion in a better way through experimental animation courses?

First, make students observe an movement of people (things) around them and draw dynamic lines by means of impression, thus make them draw a motion sketch. In order to let students observe motion of people better in class, I prepare a mirror for them and let them observe their motions in the mirror and draw a breakdown drawing.

Second, as to some abstract motion law, I use creation method of stop-motion animation to help students understand. For example, in order to make students understand motion law of growth, I ask students to imagine themselves as a seed and I give them language notes on the side. I let them use their body to deduce how a seed sprouts gradually in soil with nutrition of rain and struggles to burst out from soil. It gradually grows leaves with sunshine, blossoms and yields fruit after weatherbeaten thriving. The whole process is deduced by students through their imagination. I use a camera to shoot every step of their movement and play these pictures successively through projector. Apart from experiencing growth of life by sense organ, they also see the abstract law of motion visually. Then, through facsimileing motion law breakdown drawing of plant growth in material, they can understand this motion law accurately.

At last, make students of animation major do plenty of two-dimensional drawing homework. Of course, the process is boring and dull. Some students might mechanically facsimile those motion laws. Once breaking away from those models, they can draw nothing. In order to make students draw correct motion laws without models, I ask them to prepare a small notebook (with no need for big size, for example, memo) and design a role (or some natural phenomena). This role doesn't have to be too complex. They need to design a series of movements for this role and draw every movement on their prepared notebook (Of course, it should conform to correct motion law). Upon completion of drawing, they rapidly flip the notebook and their designed role becomes "alive" and moves on the paper. Through this method, students' activity is enhanced and they can flexibly apply written motion laws in daily homework. In fact, it is also a manifestation of experimental animation. 


\section{Motivate StUdents' InTEREST AND ENHANCE THEIR CREATION ENTHUSIASM}

The so-called experimental animation is a kind of short film with originality, free play of personal style and philosophical thought. Then, experimental animation shouldn't rigidly adhere to traditional animation mode. It needs breakthroughs in creation form, material, pattern of manifestation and conveyed thought. Apart from requiring students to master necessary theoretical knowledge, we should fully motivate students' learning interest and innovative sense, and enhance their enthusiasm of creation.

\section{A. Create an Innovative Classroom Atmosphere}

Experimental animation short film creation is a course directly turning from animation theory to practice. It is also an important process to turn innovative thought into artistic form. Compared with business animation, experimental animation has wider creation space, facilitating free play of personal innovative ability. Conventional teaching method can't motivate students' innovative sense. Only teachers with innovative thought can cultivate students with innovative sense. Experimental animation's daily teaching activity should break through traditional classroom teaching model. Playground can be used as teaching place, making students create with the help of natural environment and things. We can use some small stage properties which can be found without extra trouble in teaching, such as gloves, disposable paper cup, candle and so on. Then students can create according to different properties of materials. In a word, experimental animation's teaching mode has to break away from those old-fashioned methods. "Playing games" can run through the whole process of course teaching, thus motivating students' learning enthusiasm and enhancing their operational ability. "Fig. 1"

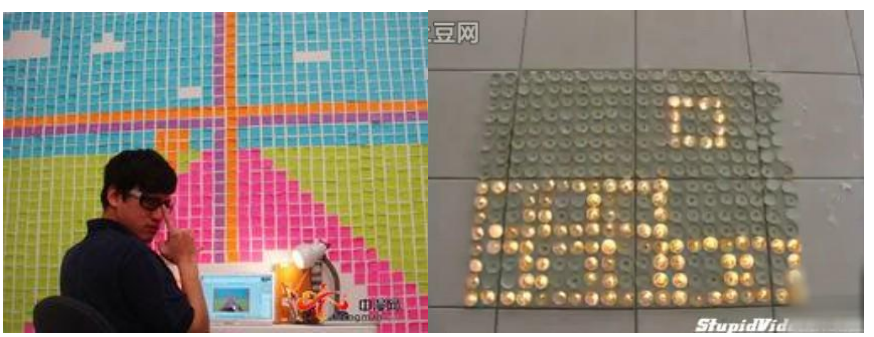

Fig. 1. Works based on different materials

\section{B. Motivate Students'Imagination}

Ancient Greek philosopher Aristotle says: Imagination is the source of invention, discovery and all other creative activities. As a manifestation form of art, animation requires students to give full play to their personal imagination, especially experimental animation. Experimental animation itself is a kind of exploration on animation art, thus it can't do without creator's imagination.

Students are different from each other. Some students have rich imagination while some students have relatively fixed thinking modes and lack imagination. My method of work is letting those students with rich imagination mobilize atmosphere of the whole classroom, thus making those students who don't like using their minds active. In classroom teaching, I let students combine with each other freely to fall into groups. Group members discuss and they take turns making a statement. Statement content is recorded. Finally, they extract the most excellent idea unanimously and report it to the teacher and students. Other students can put forward their own view and opinion on the basis of their creativity. At the end, the teacher gives comments and further enlightens students to form a final scheme. Then, the scheme is produced through manifestation form of experimental animation. Practice has proved: This method can motivate students' enthusiasm in making short films and expand students' imagination space.

\section{Enhance Students' Aesthetic Ability AND ARTISTIC CULTURE}

Animation is a special type of film. Like film, animation also belongs to audio-visual art scope. It absorbs artistic means and skills of literature, painting, sculpture, architecture, music, play and so on to the utmost. It combines spatial art and time art well to display life comprehensively. In experimental animation class, apart from imparting theoretical knowledge, I also make efforts in enhancing students' artistic culture. Before short film creation, I call for students to firstly experience life and extract useful materials from it. I ask them to read many books, practice a lot and have contact with knowledge of different artistic classes at ordinary times. Only by doing this, can they can distinctive views in the field of experimental animation. It is not difficult for people who have seen a series of Miyazaki Hayao's works to discover that depictions of sky scene and various air vehicles run through his works. It is exactly because that Miyazaki Hayao's father has worked in an aircraft factory. From childhood, Miyazaki Hayao yearns for flying and sky, and that's why he can vividly depict those air vehicles. The fact that Miyazaki Hayao becomes a legend in animation world also benefits from his passion and obsession with animation since childhood. Therefore, in daily teaching, I often recommend some good books and films to students, hoping to enhance their culture in learning. "Fig. 2"

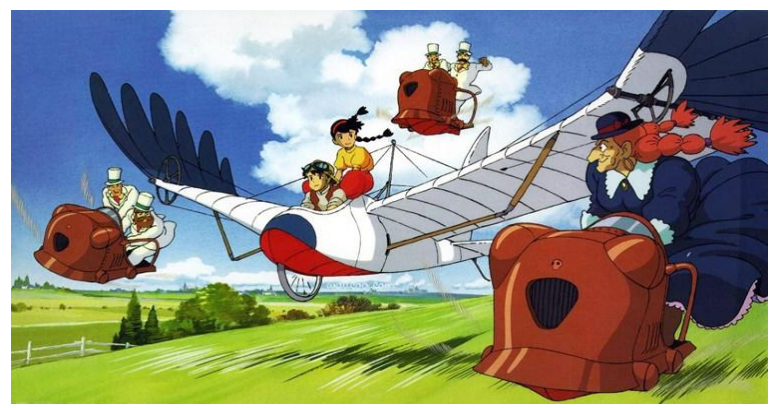

Fig. 2. The cartoon created by Miyazaki Hayao

Experimental animation expresses spiritual essence of things through transformation, humor and absurdness, and passes on literature and philosophical idea to people. Appreciator can have aesthetic pleasure and pleasant sensations through conceptual work and form aesthetic taste. Many experimental animation short films don't have exquisite scenes, gorgeous colors or vivid modeling and they have many 
rugged lines and simple modeling. We can't say that rough modeling is ugly and lovely modeling is beautiful. In art works, beauty and ugliness are relative. Therefore, students need to have certain aesthetic ability. They can't appreciate a work from its surface and give comments. Besides, at present, many students put their learning emphasis on Microsoft and think that they can do animation well through mastering a few Microsofts. They neglect cultivation of personal artistic appreciation ability. During his artistic career, Norman Maclaren, Canadian animation godfather, wins 147 awards. All of his works are experimental animation. Many works' core lies in research on motion and rhyme. He experiments with large quantities of various materials and sounds. Pure abstract pictures, colors and music make up flowing visual symphonies. Mosaic is such a pure abstract work and it consists of many colorful cubes dancing to the sound. Of course, he has many other excellent animation works which similarly use some abstract pictures and even exaggerated modeling to display. Can you say that such works aren't beautiful?

\section{CONCLUSION}

In a word, experimental animation teaching needs to break through traditional teaching mode and abandon cramming teaching method and the traditional idea that as long as students master theoretical knowledge of experimental short film creation, it is good. We should let "experimental" run through daily teaching activities and let students give full play to their innovative ability through a series of little experiments. Let students create short films which are innovative either in manifestation form or in style and let them have a better understanding of the essence of animation through learning in experimental animation course.

\section{REFERENCES}

[1] Zhu Youhua. Experimental Animation Short Film Teaching Method Research [G]. Popular Literature. Artist Edition, 2010.08.

[2] Tang Yucheng. Stop-Motion Animation. Southwest Normal University Press

[3] He Wei, Li Hongqin. Manifestation of Artistic Beauty in Animation Creation [J]. Film Literature, 2010.02.

[4] Liu Jingjing. Experimental Animation Short Film Teaching Method Research [J]. Shanxi Education (Theoretic Version), 2006.Z1. 